\section{Psychological Medicine}

cambridge.org/psm

\section{Correspondence}

Cite this article: Pignon $B$, Geoffroy PA, Thomas P, Roelandt J-L, Amad A (2019). Environment risk factors have different impact on bipolar and psychotic disorders: an analysis of MHGP survey. Psychological Medicine 49, 1229-1232. https://doi.org/10.1017/ S0033291719000229

Received: 10 January 2019

Revised: 16 January 2019

Accepted: 21 January 2019

First published online: 20 February 2019

\section{Key words:}

Psychotic disorders; bipolar disorders; migration; trauma; substance use disorders

Author for correspondence:

Baptiste Pignon,

E-mail: baptistepignon@yahoo.fr

\section{Environment risk factors have different impact on bipolar and psychotic disorders: an analysis of MHGP survey}

\author{
Baptiste Pignon ${ }^{1,2,3}$, Pierre A. Geoffroy ${ }^{4}$, Pierre Thomas 5,6 , Jean-Luc Roelandt ${ }^{7}$ \\ and Ali Amad $5,6,8$
}

${ }^{1}$ AP-HP, DHU PePSY, Hôpitaux universitaires Henri-Mondor, Pôle de Psychiatrie, Créteil 94000, France; ${ }^{2}$ Inserm, U955, team 15, Créteil 94000, France; Fondation FondaMental, Créteil 94000, France; ${ }^{3}$ UPEC, Université Paris-Est, Faculté de médecine, Créteil 94000, France; ${ }^{4}$ Paris Diderot Université - Paris VII, 5 Rue Thomas Mann, 75013 Paris, France; ${ }^{5}$ Univ. Lille, CNRS UMR 9193-PsyCHIC-SCALab, \& CHU Lille, Pôle de Psychiatrie, Unité CURE, F-59000 Lille, France; ${ }^{6}$ Fédération régionale de recherche en santé mentale (F2RSM) Nord-Pas-de-Calais; F-59000 Lille, France; ${ }^{7}$ EPSM Lille Métropole; Centre Collaborateur de l'Organisation Mondiale de la Santé pour la recherche et la formation en santé mentale; Équipe Eceve Inserm UMR 1123, Lille, France and ${ }^{8}$ King's College London, Institute of Psychiatry, Psychology and Neuroscience, London, UK

\section{Dear Editor}

Dykxhoorn et al. (2018) recently analysed the Swedish registers and calculated the incidence of (i) affective and non-affective psychotic disorders and (ii) non-psychotic bipolar disorder, according to migrant status among residents born between 1982 and 1996. They found that all psychotic disorders were significantly elevated among first- and second-generation migrants (1GM and 2GM), including schizophrenia and schizoaffective disorders, affective psychotic disorder and other non-affective psychotic disorders. Moreover, the incidence of non-psychotic bipolar disorder was significantly reduced among 1GM and non-significantly different among 2GM. Authors concluded to a specific effect of the migrant-related exposures on the risk of psychotic disorders as no effects were observed for non-psychotic bipolar disorders.

We read with interest this study that adds to the literature highlighting continuities and discontinuities between psychotic and bipolar disorders. Based on clinical overlaps and multi-scale similarities, some authors have argued for going beyond the Kraepelinian dichotomy and for pooling in a single entity these two diagnoses of psychotic and bipolar disorders (Guloksuz and van Os, 2018). Interestingly, several studies have suggested the involvement of partially shared and partially different environmental exposures between these disorders (Demjaha et al., 2012).

To disentangle these shared and specific environmental risk factors, studies that focus on different risk factors and different disorders are required. Moreover, these studies should also consider separately psychotic bipolar disorders, i.e. a phenotype considered as intermediate between non-psychotic bipolar disorder and psychotic disorder. Mental Health in General Population (MHGP) survey offers such an opportunity. Moreover, it allows for the first time to study the third-generation of migrants (3GM). Thus, the aim of the present study was to compare the influence of different environment risk factors [migrant status, history of trauma, substance use disorders (SUDs) and alcohol use disorders (AUDs)] on the prevalence of psychotic disorders, and of psychotic and non-psychotic bipolar disorder in the MHGP survey.

The MHGP survey, conducted by the World Health Organization Collaborating Centre, interviewed 38694 subjects selected by a quota sampling method in France between 1999 and 2003 (47 sites). For each subject, the Mini International Neuropsychiatric Interview (MINI) was used to screen for $10^{\text {th }}$ International Classification of Diseases defined psychiatric disorders in the general population. To define bipolar disorders with and without psychotic symptoms, the seven psychotic symptoms of the psychotic disorders section were used. Further details on MHGP survey and diagnoses procedures are available elsewhere (Amad et al., 2013; Pignon et al., 2017, 2018).

To compare specifically subjects with psychotic disorders to those with bipolar disorders, subjects with both diagnoses were excluded. Four groups were defined: psychotic disorders, bipolar disorders with psychotic symptoms (i.e. psychotic bipolar disorders), non-psychotic bipolar disorders and 'control' subjects without psychotic or bipolar disorders. We performed logistic regression analyses to compare the different risk factors between the four groups, defining the control group as reference. We controlled these analyses for age, sex, and educational, income and marital status. All statistical analyses were performed using R software version 3.1.0 (http://www.R-project.org).

Of the 38694 individuals interviewed, 140 subjects were excluded because of dual diagnoses of bipolar and psychotic disorders ( $0.36 \%$ of the total sample). At the end, 474 subjects with bipolar disorders, including 293 without psychotic symptoms (0.76\%) and 181 with psychotic symptoms (0.47\%), and 933 subjects with psychotic disorders (2.42\%) were analysed. 
Table 1. Logistic regression analyses* ${ }^{\star}$ to compare subjects with psychotic and non-psychotic bipolar disorder, and psychotic disorders, to subjects without bipolar or psychotic disorder

\begin{tabular}{|c|c|c|c|c|c|c|c|c|c|c|c|c|c|c|c|c|c|c|c|c|}
\hline & \multicolumn{2}{|c|}{$\begin{array}{l}\text { Controls ( } n=37 \\
147 \text { ) (reference) }\end{array}$} & \multicolumn{6}{|c|}{ Non-psychotic bipolar disorder $(n=293)$} & \multicolumn{6}{|c|}{ Psychotic bipolar disorder $(n=181)$} & \multicolumn{6}{|c|}{ Psychotic disorder $(n=933)$} \\
\hline & N & $\%$ & N & $\%$ & $\mathrm{OR}$ & $\begin{array}{l}95 \% \\
\mathrm{Cl}-\end{array}$ & $\begin{array}{l}95 \% \\
\mathrm{Cl}+\end{array}$ & $p$ & N & $\%$ & OR & $\begin{array}{l}95 \% \\
\mathrm{Cl}-\end{array}$ & $\begin{array}{l}95 \% \\
\mathrm{Cl}+\end{array}$ & $p$ & N & $\%$ & $\mathrm{OR}$ & $\begin{array}{l}95 \% \\
\mathrm{Cl}-\end{array}$ & $\begin{array}{l}95 \% \\
\mathrm{Cl}+\end{array}$ & $p$ \\
\hline \multicolumn{21}{|l|}{ Age band } \\
\hline $18-29$ years & 9216 & 24.8 & 114 & 38.9 & 3.76 & 2.10 & 6.75 & $<0.001$ & 46 & 25.4 & 1.80 & 0.95 & 3.40 & 0.072 & 298 & 31.9 & 1.44 & 1.09 & 1.92 & 0.011 \\
\hline $30-44$ years & 10578 & 28.5 & 108 & 36.9 & 3.93 & 2.28 & 6.77 & 0.002 & 72 & 39.8 & 2.53 & 1.46 & 4.38 & $<0.001$ & 302 & 32.4 & 1.82 & 1.41 & 2.35 & $<0.001$ \\
\hline $45-59$ years & 8121 & 21.9 & 48 & 16.4 & 2.40 & 1.37 & 4.23 & 0.002 & 35 & 19.3 & 1.52 & 0.86 & 2.69 & 0.153 & 191 & 20.5 & 1.77 & 1.37 & 2.29 & $<0.001$ \\
\hline $\begin{array}{l}\text { 60+years } \\
\text { (reference) }\end{array}$ & 9232 & 24.9 & 23 & 7.8 & - & - & - & - & 28 & 15.5 & - & - & - & - & 142 & 15.2 & - & - & - & - \\
\hline \multicolumn{21}{|l|}{ Gender } \\
\hline Male (reference) & 17057 & 45.9 & 172 & 58.7 & - & - & - & - & 106 & 58.6 & - & - & - & - & 470 & 50.4 & - & - & - & - \\
\hline Female & 20090 & 54.1 & 121 & 41.3 & 0.80 & 0.62 & 1.03 & 0.372 & 75 & 41.4 & 0.75 & 0.55 & 1.03 & 0.073 & 463 & 49.6 & 1.08 & 0.94 & 1.25 & 0.255 \\
\hline \multicolumn{21}{|l|}{ Education level } \\
\hline $\begin{array}{l}\text { No education - } \\
\text { elementary level }\end{array}$ & 8959 & 24.1 & 49 & 16.7 & 1.21 & 0.80 & 1.83 & 0.372 & 42 & 23.2 & 1.70 & 1.03 & 2.80 & 0.037 & 192 & 20.6 & 1.10 & 0.88 & 1.39 & 0.406 \\
\hline Secondary level & 18177 & 48.9 & 170 & 58 & 1.15 & 0.86 & 1.53 & 0.349 & 97 & 53.6 & 1.31 & 0.89 & 1.92 & 0.164 & 505 & 54.1 & 1.10 & 0.93 & 1.30 & 0.43 \\
\hline $\begin{array}{c}\text { University level } \\
\text { (reference) }\end{array}$ & 10011 & 26.9 & 74 & 25.3 & - & - & - & - & 42 & 23.2 & - & - & - & - & 236 & 25.3 & - & - & - & - \\
\hline \multicolumn{21}{|l|}{ Marital status } \\
\hline $\begin{array}{c}\text { Married } \\
\text { (reference) }\end{array}$ & 20322 & 55.2 & 112 & 38.2 & - & - & - & - & 79 & 43.9 & - & - & - & - & 348 & 37.5 & - & - & - & - \\
\hline Never married & 10120 & 27.5 & 126 & 43 & 1.25 & 0.92 & 1.72 & 0.159 & 62 & 34.4 & 1.55 & 1.03 & 2.33 & 0.036 & 402 & 43.3 & 1.75 & 1.46 & 2.09 & $<0.001$ \\
\hline Separated & 2971 & 8.1 & 48 & 16.4 & 2.43 & 1.69 & 3.50 & $<0.001$ & 27 & 15.0 & 2.22 & 1.40 & 3.55 & $<0.001$ & 118 & 12.7 & 1.75 & 1.40 & 2.19 & $<0.001$ \\
\hline Widowed & 3430 & 9.3 & 7 & 2.4 & 0.76 & 0.32 & 1.77 & 0.520 & 12 & 6.7 & 1.57 & 0.77 & 3.20 & 0.212 & 61 & 6.6 & 1.21 & 0.87 & 1.67 & 0.258 \\
\hline \multicolumn{21}{|l|}{ Income level $^{\mathrm{a}}$} \\
\hline Low & 13685 & 37.9 & 145 & 51.2 & 1.59 & 1.10 & 2.29 & 0.012 & 68 & 38.0 & 0.79 & 0.50 & 1.24 & 0.298 & 482 & 53.4 & 1.63 & 1.32 & 2.01 & $<0.001$ \\
\hline Medium & 14589 & 40.4 & 93 & 32.9 & 1.05 & 0.73 & 1.25 & 0.777 & 75 & 41.9 & 0.94 & 0.62 & 1.42 & 0.760 & 279 & 30.9 & 1.02 & 0.82 & 1.25 & 0.908 \\
\hline High (reference) & 7846 & 21.7 & 45 & 15.9 & - & - & - & - & 36 & 20.1 & - & - & - & - & 141 & 15.6 & - & - & - & - \\
\hline \multicolumn{21}{|l|}{ Migrant status } \\
\hline Native (reference) $^{\mathrm{b}}$ & 27722 & 74.6 & 200 & 68.3 & - & - & - & - & 135 & 74.6 & - & - & - & - & 593 & 63.6 & - & - & - & - \\
\hline $1 G M$ & 1943 & 5.2 & 16 & 5.5 & 0.93 & 0.55 & 1.59 & 0.793 & 14 & 7.7 & 1.41 & 0.80 & 2.46 & 0.232 & 75 & 8.0 & 1.62 & 1.26 & 2.08 & $<0.001$ \\
\hline $2 \mathrm{GM}$ & 3944 & 10.6 & 39 & 13.3 & 0.88 & 0.61 & 1.27 & 0.491 & 16 & 8.8 & 0.70 & 0.41 & 1.18 & 0.181 & 131 & 14.0 & 1.24 & 1.02 & 1.52 & 0.032 \\
\hline $3 G M$ & 3538 & 9.5 & 38 & 13 & 1.02 & 0.71 & 1.46 & 0.908 & 16 & 8.8 & 0.78 & 0.46 & 1.32 & 0.350 & 134 & 14.4 & 1.43 & 1.17 & 1.74 & $<0.001$ \\
\hline
\end{tabular}




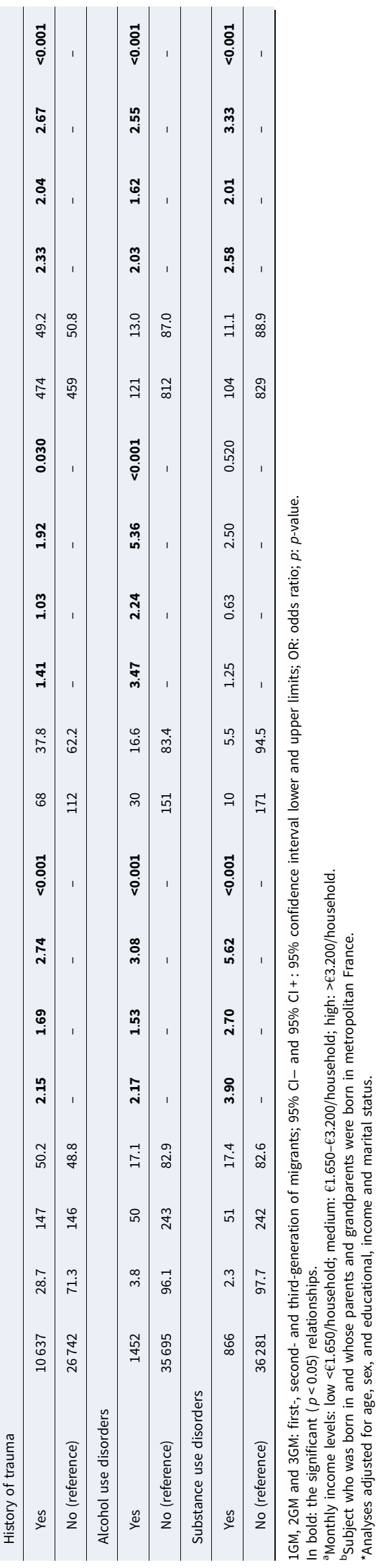

Table 1 shows sociodemographic and clinical characteristics of the four groups. The rates of migrants (1GM, $2 \mathrm{GM}$ and $3 \mathrm{GM}$ ) were higher among subjects with psychotic disorders (ORs between 1.52 and 2.08), in contrast to the rates of migrants in psychotic and non-psychotic bipolar disorders groups. Rates of subjects with a history of trauma were higher in the three groups (ORs between 1.41 and 2.33). Likewise, for AUDs (ORs between 2.03 and 3.47). The rates of subjects with SUDs were higher among the subjects with non-psychotic bipolar disorders $(\mathrm{OR}=$ $3.90)$ and among subjects with psychotic disorders $(\mathrm{OR}=2.58)$.

These results confirm the Demjaha et al. (2012) observation suggesting that, between bipolar and psychotic disorders, environment exposures involved are partially shared and partially different. Our results are also consistent with Dykxhoorn et al.'s study on the different effects of migrant-related exposures on the two types of disorders: $1 \mathrm{GM}$ and $2 \mathrm{GM}$ status were associated with increased incidence of psychotic disorders and not with nonpsychotic bipolar disorders. However, unlike Dykxhoorn et al., we did not find any association between migrant status and the frequency of psychotic bipolar disorders. Interestingly, a recent meta-analysis of six studies considering the risk of mood disorder among migrants did not find any association between 1GM status and bipolar disorder (Mindlis and Boffetta, 2017). Our study also presents data concerning $3 \mathrm{GM}$, also showing increased rates of psychotic disorders but not bipolar disorders, including those with psychotic symptoms, among migrants.

The history of trauma has been widely studied in the scientific literature that shows an increased risk associated with both psychotic and bipolar disorders (Carr et al., 2013), as found in our study. Finally, we did not find different impact of either AUDs or SUDs on psychotic or bipolar disorders prevalences. This is in line with actual knowledge of an increased risk for both disorders regarding SUDs that could represent an unspecific risk factor of both bipolar and psychotic disorders (Demjaha et al., 2012).

Of note, several other environment factors are known to have a different impact on bipolar and psychotic disorders. Urbanicity, one of the oldest and best acknowledged risk factor of psychotic disorders (March et al., 2008), has a slight or null effect on the risk of bipolar disorder (Mortensen et al., 2003). Studies of urban neighbourhood variations of incidence and prevalence also showed different patterns for affective and non-affective psychotic disorders (March et al., 2008). Obstetric complications, advanced paternal age or birth in winter are more or less in the same situation (Demjaha et al., 2012).

Overall, the MHGP survey allowed to compare risk factors across a continuum ranging from bipolar disorder without psychotic features to psychotic disorders and observed the involvement of shared and specific environmental risk factors in these disorders with or without psychotic symptoms.

Author ORCIDs. (D) Baptiste Pignon, 0000-0003-0526-3136.

Financial support. No funding was secured for this study.

Conflict of interest. None.

\section{References}

Amad A, Guardia D, Salleron J, Thomas P, Roelandt J-L and Vaiva G (2013) Increased prevalence of psychotic disorders among third-generation migrants: results from the French mental health in general population survey. Schizophrenia Research 147, 193-195.

Carr CP, Martins CMS, Stingel AM, Lemgruber VB and Juruena MF (2013) The role of early life stress in adult psychiatric disorders: a systematic review 
according to childhood trauma subtypes. The Journal of Nervous and Mental Disease 201, 1007.

Demjaha A, MacCabe JH and Murray RM (2012) How genes and environmental factors determine the different neurodevelopmental trajectories of schizophrenia and bipolar disorder. Schizophrenia Bulletin 38, 209-214.

Dykxhoorn J, Hollander A-C, Lewis G, Magnusson C, Dalman C and Kirkbride JB (2018) Risk of schizophrenia, schizoaffective, and bipolar disorders by migrant status, region of origin, and age-at-migration: a national cohort study of 1.8 million people. Psychological Medicine (in press) 1-10. doi: $10.1017 / S 0033291718003227$.

Guloksuz S and van Os J (2018) The slow death of the concept of schizophrenia and the painful birth of the psychosis spectrum. Psychological Medicine 48, 229-244.

March D, Hatch SL, Morgan C, Kirkbride JB, Bresnahan M, Fearon P and Susser E (2008) Psychosis and place. Epidemiologic Reviews 30, 84-100.
Mindlis I and Boffetta P (2017) Mood disorders in first- and secondgeneration immigrants: systematic review and meta-analysis. The British Journal of Psychiatry 210, 182-189.

Mortensen PB, Pedersen CB, Melbye M, Mors O and Ewald H (2003) Individual and familial risk factors for bipolar affective disorders in Denmark. Archives of General Psychiatry 60, 1209-1215.

Pignon B, Geoffroy PA, Thomas P, Roelandt J-L, Rolland B, Morgan C, Vaiva G and Amad A (2017) Prevalence and clinical severity of mood disorders among first-, second- and third-generation migrants. Journal of Affective Disorders 210, 174-180.

Pignon B, Peyre H, Szöke A, Geoffroy PA, Rolland B, Jardri R, Thomas P, Vaiva G, Roelandt J-L, Benradia I, Behal H, Schürhoff F and Amad A (2018) A latent class analysis of psychotic symptoms in the general population. Australian and New Zealand Journal of Psychiatry 52, 573-584. 